\title{
Evaluation of Effect of Various Nanofillers on Technological Properties of NBR/NR Blend Vulcanized Using BIAT-CBS System
}

\author{
Shaji P. Thomas, ${ }^{1}$ Saliney Thomas, ${ }^{2}$ C. V. Marykutty, ${ }^{3}$ and E. J. Mathew ${ }^{4}$ \\ ${ }^{1}$ Department of Chemistry, Bishop Abraham Memorial College, Thuruthicadu, Kerala 689 597, India \\ ${ }^{2}$ School of Chemical Sciences, Mahatma Gandhi University, Kerala 686560, India \\ ${ }^{3}$ Department of Chemistry, Assumption College, Changanasserry, Kerala 686101, India \\ ${ }^{4}$ Kottayam Institute of Science and Technology, Pallikkathode, Kerala 686503, India
}

Correspondence should be addressed to Shaji P. Thomas; shajiparel@gmail.com

Received 28 March 2013; Revised 2 August 2013; Accepted 13 August 2013

Academic Editor: Alan K. T. Lau

Copyright (C) 2013 Shaji P. Thomas et al. This is an open access article distributed under the Creative Commons Attribution License, which permits unrestricted use, distribution, and reproduction in any medium, provided the original work is properly cited.

\begin{abstract}
Owing to processing ease and resistance to oils and chemicals, NBR is widely used in many industries. But since neat NBR has only poor tensile properties, it is better to use suitable blends of NR and NBR after incorporating appropriate nanoingredients before vulcanization. It is well established that nanoparticles can be easily dispersed in a more uniform pattern in polymer matrix, thereby enhancing the technological properties of the elastomer vulcanizate. Since there are no systematic comparative studies on technological properties of NBR/NR blend containing different nanoingredients, efforts have been made in this study to investigate cure and technological properties like tensile properties, tear resistance, compression set, hardness, abrasion loss and swelling value of NBR/NR (80/20) blend vulcanizates containing stearic acid-coated nano-zinc oxide (ZOS), nano-BIAT, nano-silicate-coated $\mathrm{CaCO}_{3}, \mathrm{PEO}$-coated calcium silicate, and surface-modified carbon nanotubes (CNT). XRD and electron microscopy have been used for morphological analysis. The nano ingredients were effective in enhancing the technological properties of the vulcanizates. Among the nanofillers, modified CNT was found to impart superior properties to NBR/NR blend due to more intercalation.
\end{abstract}

\section{Introduction}

Owing to processing ease and resistance to oils and chemicals, NBR is widely used in many industries. However, neat NBR exhibits only poor tensile properties and oil resistance. A considerable amount of research has been made over the last several years with a view to obtaining new polymeric materials with enhanced specific attributes for specific applications. Much attention is devoted to the simplest route for combining outstanding properties of different existing polymers, that is, by blending polymers. Although increasing numbers of miscible blends are reported [1-5], most polymers are almost immiscible, thus leading to heterophase polymer blends. There are two widely used types of elastomer blends: miscible single-phase blends and immiscible two-phase blends.

It is scientifically proved that the presence of certain polymeric species with the right structure can result in compatibilization of an immiscible elastomer blend by virtue of their ability to change interfacial situation [6-8]. Such materials, known as compatibilizers, are added or in situ formed during blending of elastomers. The compatibilizers in elastomer blends perform many roles like reducing interfacial energy between the phases, permitting finer dispersion during mixing, providing stability against gross segregation, and improving interfacial adhesion. Two elastomers can form a compatible blend when they have (1) segmental structural identity, (2) miscibility/partial miscibility with each other, and (3) functional groups capable of forming covalent or other bonds between the polymers [9].

Kader et al. prepared (50/50) NR/NBR blend using transpolyacetylene rubber (TOR) as a compatibilizer [10]. They showed that inclusion of TOR in the blend altered the phase morphology by reducing the size of the NBR phase. In another study, Sirisinha et al. [11] have reported that oil 
resistance of 20/80 NR/NBR blend depended mainly on the phase morphology of the blend. The resistance to oil was higher when the size of the NR dispersed phase was smaller. Mathai et al. [12] also investigated that the equilibrium solvent uptake decreases with an increase in the concentration of NBR. Li et al. [13] investigated the effect of polysiloxane-g-octane and polysiloxane-g-(3, 7-dimethyl6-octylene) as compatibilizers in NR/SR blend system and showed that mechanical properties of the blend improved considerably when the compatibilizers were used. In another study, Angnanon et al. [14] investigated the effect of graft $\mathrm{NR}$ as a compatibilizer in the NR/NBR blend system. They also obtained a similar result as in the study conducted by Mingjun et al.

Polychloroprene (CR) has a backbone structure similar to that of NR, but it is more polar due to the presence of chlorine. The solubility parameter value of CR is an intermediate of that of NR and NBR. Also the presence of dipole within the repeat unit allows the possibility of interaction of acrylonitrile repeat unit of NBR.

Fillers like carbon black, metals, and ceramics were used to improve the technological properties of NBR [15-19]. For example, carbon blacks are excellent fillers because of their strong interaction with NBR, but the resulting materials have limitations associated with decreased processability at higher loading. Recently, silica has been used in NBR because of its good interaction and environmental issues caused by carbon black $[20,21]$. However, it is difficult to get uniform dispersion of silica particles in NBR matrix due to particle agglomeration probably caused by the polar groups on the surface of silica particles [22].

Fillers like $\mathrm{CaCO}_{3}$, clay, and so forth with average particle size of $1-100 \mathrm{~nm}$ can be used in relatively small quantities $(5 \%-10 \%)$ in order to provide substantial improvements in technological properties of elastomers. Nanoparticles can form fine and homogeneous dispersion in the polymer matrix. As compared with micron-sized particles, the nanoparticles can occupy substantially greater number of sites in the polymer matrix. Such particles increase the barrier properties by creating tortuous path that slows the progress of gas molecules through polymer matrix. Also these particles in the polymer matrix improve surface properties like gloss, surface finish, grip, and so forth. S. N. Chakravarty and A. Chakravarty reported the reinforcing and air retention effect of nano- $\mathrm{CaCO}_{3}$ in (70/30) NBR/NR blend [23]. Effect of different nanoparticles on thermal, mechanical, and dynamic mechanical properties of HNBR nanocomposites was studied by Choudhury et al. [24]. Thomas also investigated the effect of calcium phosphate, titanium dioxide, and layered silicate on the technological properties of NBR nanocomposites [25]. Recently carbon nanotubes (CNTs) have become attractive due to the possibility of large-scale production of these materials. CNTs possess several advantages in industries like cost effectiveness and light weight of the article produced due to the requirement of these fillers in much lower dosages to achieve good technological properties [24-34]. The exceptional properties of CNTs like high mechanical strength, flexibility, and impressive electrical and thermal conductivity make them attractive and potential candidates for various applications [35-37]. Despite these outstanding properties, there are two main limitations which prevent their easy use. The surface energy of CNTs is significantly different from that of the matrix of polymer or similar organic compounds, and as a result, the finer dispersion of CNTs into the matrix is quite a difficult task [38]. Also, the seamless surface of CNTs cannot provide physical interaction between CNTs and the matrix [39]. The modification of CNTs using suitable compounds makes them interesting and apt candidates for a plethora of applications including nanoelectronics [40]. In a study by Ali et al. [41], it was observed that the presence of nanoclay influenced the morphology of HNBR/NR blend to the extent that a change from the cocontinuous phase morphology into the islandmatrix morphology occurred. Although better dispersion of CNTs in elastomer is possible by solution mixing [42, 43], it is not suitable for industrial applications owing to the requirement of hazardous solvents in large quantities which in turn makes the method less economic. Better dispersion of comparatively lower dosage of nanofillers in elastomers is also possible by two-roll mixing. The shear force developed at $80^{\circ} \mathrm{C}$ in the two-roll mill is sufficient to cause uniform dispersion.

Since there are no systematic and comparative studies on the use and effect of nanomodified accelerator, stearic acidcoated nano-zinc oxide (ZOS), silicate-coated nano- $\mathrm{CaCO}_{3}$ (SCC), PEO-coated calcium silicate (PCS), and carbon nanotubes (CNTs) on vulcanizate properties of NBR/NR blend, efforts have been made in this study to compare the technological properties of $80 / 20 \mathrm{NBR} / \mathrm{NR}$ blend nanocomposites containing these nanoparticles. This particular blend has been taken for the study because an earlier study [11] reported better oil resistance for it. XRD and electron microscopy have been used for morphological analysis.

\section{Experimental}

Different NR/NBR blend (20/80) compounds were prepared using the ingredients as shown in Table 1, on a laboratory-size two-roll mill $(15.3 \times 30.5 \mathrm{~cm}$, Indian Expeller $)$ as per ASTM designation D3182-89. NBR (33\% acrylonitrile content, grade N-684) was masticated for $2 \mathrm{~min}$, and the nanofiller/compatibilizer/antioxidant were added to the masticated NBR. The mixing was continued for $5 \mathrm{~min}$ and previously masticated NR (ISNR-5) and ZOS were added to this NBR, and again mixing was continued for another $3 \mathrm{~min}$. Finally, accelerators followed by sulfur were also added, and mixing was continued to get a homogeneous rubber compound.

All the mixes from $\mathrm{NBCNT}_{1}$ to $\mathrm{NB}_{0}$ contain $\mathrm{NBR}$ and $\mathrm{NR}$ in $80: 20$ proportion, 5 phr of ZOS, $1.32 \mathrm{phr}$ ( 5 mmols) of CBS, $1.3425 \mathrm{phr}$ (7.5 mmols) of BIAT, and $1.5 \mathrm{phr}$ of sulfur. The mix $\mathrm{NBCNT}_{1}$ to $\mathrm{NBCNT}_{4}$ contains $1,3,5$, and 7 phr of CNT as nanofiller. NBCS contains $7 \mathrm{phr}$ of nano-PCS as filler. NBCC contains 7 phr of nano-SCC as filler. The mix $\mathrm{NB}_{0}$ contains 2 phr of CR as compatibilizer, and no nanofiller is present in it. Since the maximum concentration of CNT has been limited as 7 phr, other prepared nanofillers (PCS and SCC) have also been taken in the limiting concentrations of $7 \mathrm{phr}$. 
TABLE 1: NBR/NR blend formulations containing nano-SCC, -PCS, and CNT.

\begin{tabular}{|c|c|c|c|c|c|c|c|}
\hline \multirow{2}{*}{ Ingredients in phr } & \multicolumn{7}{|c|}{ Mixes } \\
\hline & $\mathrm{NBCNT}_{1}$ & $\mathrm{NBCNT}_{2}$ & $\mathrm{NBCNT}_{3}$ & $\mathrm{NBCNT}_{4}$ & NBCC & NBCS & $\mathrm{NB}_{0}$ \\
\hline NR & 20 & 20 & 20 & 20 & 20 & 20 & 20 \\
\hline NBR & 80 & 80 & 80 & 80 & 80 & 80 & 80 \\
\hline $\mathrm{CR}$ & 0 & 0 & 0 & 0 & 0 & 0 & 2 \\
\hline ZOS & 5 & 5 & 5 & 5 & 5 & 5 & 5 \\
\hline TDQ & 1 & 1 & 1 & 1 & 1 & 1 & 1 \\
\hline CNT & 1 & 3 & 5 & 7 & 0 & 0 & 0 \\
\hline $\mathrm{n}-\mathrm{SCC}$ & 0 & 0 & 0 & 0 & 7 & 0 & 0 \\
\hline n-PCS & 0 & 0 & 0 & 0 & 0 & 7 & 0 \\
\hline CBS & 1.32 & 1.32 & 1.32 & 1.32 & 1.32 & 1.32 & 1.32 \\
\hline n-BIAT & 1.3425 & 1.3425 & 1.3425 & 1.3425 & 1.3425 & 1.3425 & 1.3425 \\
\hline S & 1.5 & 1.5 & 1.5 & 1.5 & 1.5 & 1.5 & 1.5 \\
\hline
\end{tabular}

Accelerators are taken in phr corresponding to mols.

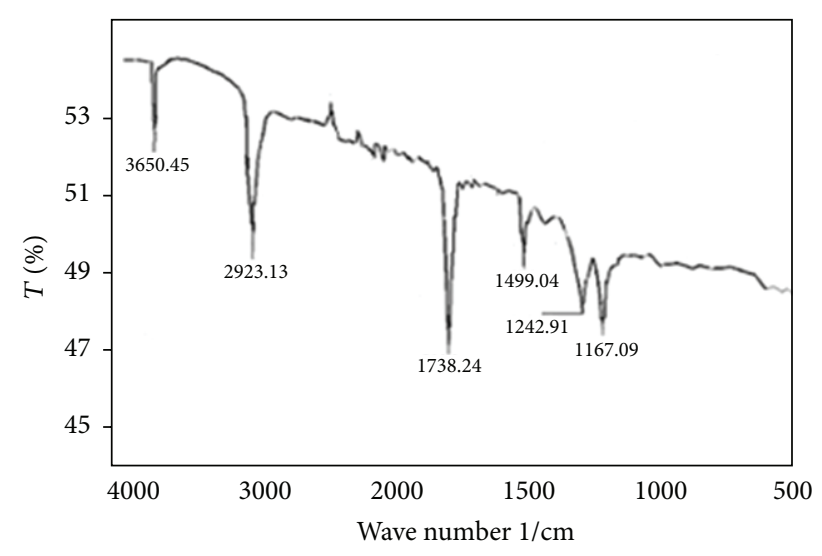

FIGURE 1: FTIR spectrum of modified MWCNT.

\section{Results and Discussion}

\subsection{Characterization}

3.1.1. FTIR Spectroscopy. The FTIR spectrum of CNT is given in Figure 1. The IR spectrum of the compound was taken on Shimadzu FTIR spectrometer. About $5 \mathrm{mg}$ of the pure sample was pelletized with $\mathrm{KBr}$, and then, the spectrum was taken. The peak at $1738 \mathrm{~cm}^{-1}$ is due to carbonyl group. The peak at $3650.45 \mathrm{~cm}^{-1}$ can be assigned to $-\mathrm{OH}$ group. The peaks at 2857 and $2928 \mathrm{~cm}^{-1}$ are due to $\mathrm{C}-\mathrm{H}$ stretching of aromatic ring attached to CNT by modification [44].

3.1.2. XRD Analysis. The XRD spectra are given in Figure 2. $\mathrm{X}$-ray diffraction patterns of the samples were taken on Bruker $\mathrm{AXS}_{8}$ advance model XRD instrument, with source $\mathrm{Cu}$, wavelength $1.5406 \AA$, and $\mathrm{Si}$ (Li) PSD detector. The peaks at 28.5 and 38.5 in Figure 2(f) are due to nano-calcium carbonate intercalated into polymer matrix. Tavangar et al. [45] and Mishra and Shimpi [46] reported peaks at angles 29, $39,47.5$, and $48.5^{\circ}$ (2 $\theta$ scale) for (104), (113), (018), and (116) planes, respectively, for free nano- $\mathrm{CaCO}_{3}$ (Figure $2(\mathrm{~g})$ ). The slight shift from these values in the case of the XRD spectrum of NBCC (Figure 2(f)) could be due to intercalation. Other peaks are due to $\mathrm{ZnO}$. Gupta et al. reported peaks at 31.7, 34.4, $36.2,47.5,56.6$, and $62.9^{\circ}$ for the various planes of $\mathrm{ZnO}$ [47].

In the XRD spectra of all of the CNT-filled NBR/NR blend vulcanizates (Figures 2(b)-2(e)), less intense peak at $24.7^{\circ}$ is due to the intercalated CNT. Khairurrijal et al. reported a peak at $25.5^{\circ}$ for (002) planes of CNT fabricated using spray pyrolysis [48]. Li et al. also reported a peak at $25.9^{\circ}$ for pure CNT (Figure 2(a)) [49]. The reduction in intensity and also the shift from the expected angle from $25.9^{\circ}$ to $24.7^{\circ}$ in the present case could be due to intercalation as evident from the SEM and TEM images (Figure 3). The peak at $24.7^{\circ}$ becomes broader and less intense as the concentration of CNT increases due to more intercalation.

3.1.3. Microscopic Analysis. The morphological analysis of representative vulcanizates of NBR/NR blend mixes was done using microscopic methods like SEM, TEM, and AFM and the micrographs are given in Figure 3. Scanning electron microscopic images of the samples were taken using Jeol SEM $(10 \mathrm{KV})$. The foldings found in the SEM image of $\mathrm{NBCNT}_{1}$ (Figure 3(a)) could be due to the lower NBR/NR miscibility. The white patches are due to agglomerated nanoparticles of $\mathrm{ZnO}$ and BIAT. These types of foldings are not found in the SEM image of $\mathrm{NBCNT}_{4}$ (Figure 3(b)), due to the enhanced compatibilizing action of carboxylated CNT as its concentration increases. The white patches found in the SEM image of NBCC (Figure 3(c)) are also due to the nanoparticles of SCC, $\mathrm{ZnO}$, and BIAT dispersed in the rubber matrix. The SEM images of the fractured surface of $\mathrm{NBCNT}_{1}$ and $\mathrm{NBCNT}_{4}$ (Figures 3(d) and 3(e)) show the sliding of rubber chains over CNTs.

Transmission electron microscopic images of the samples were taken on Jeol JEM-2100 HRTEM $(200 \mathrm{kV}$, beam current $104.2 \mu \mathrm{A})$. The TEM images of vulcanized rubber samples were taken after preparing ultrathin sections of samples using ultramicrotome (Leica EM FCS Ultracut) with cryosystem. The TEM image of $\mathrm{NBCNT}_{1}$ (Figure $3(\mathrm{f})$ ) shows welldispersed curled CNTs. As the concentration of CNTs reaches 

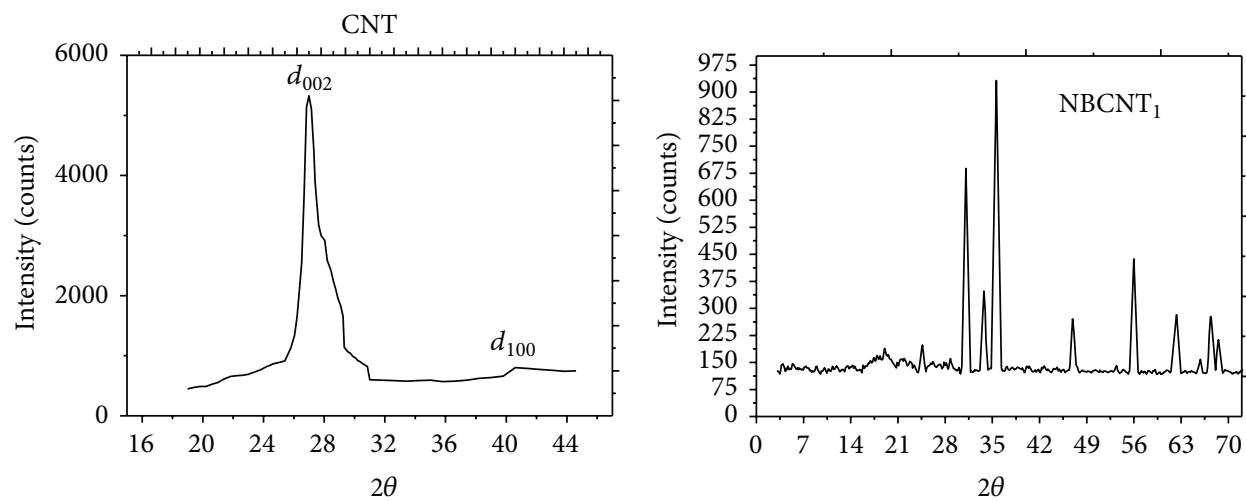

(a)

(b)
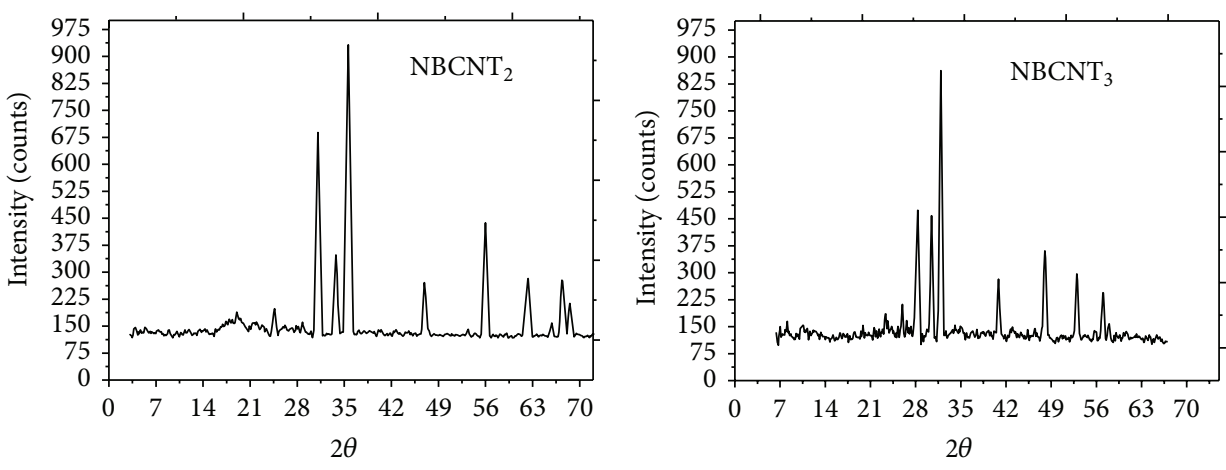

(c)

(d)
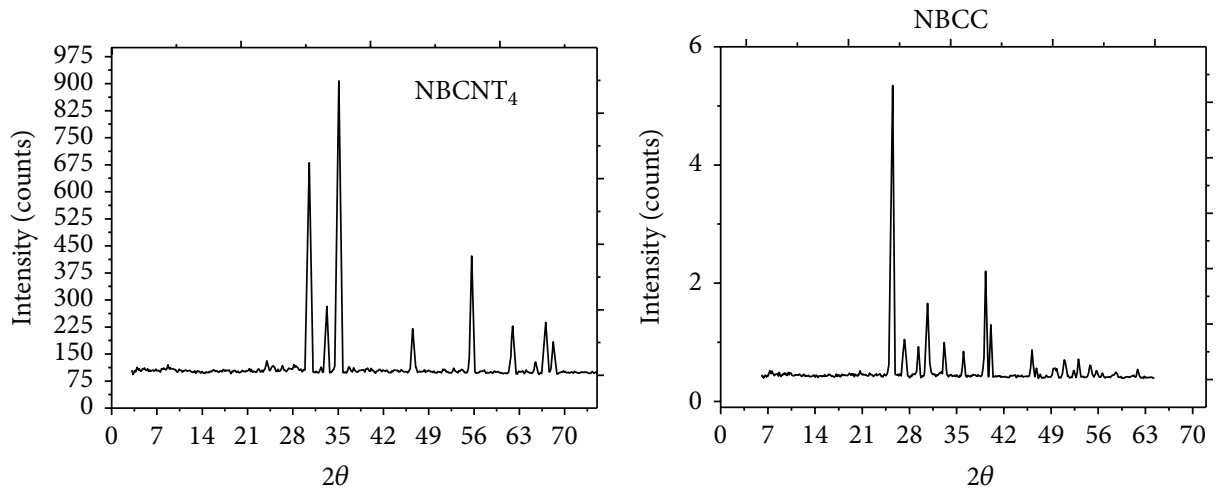

(e)

(f)

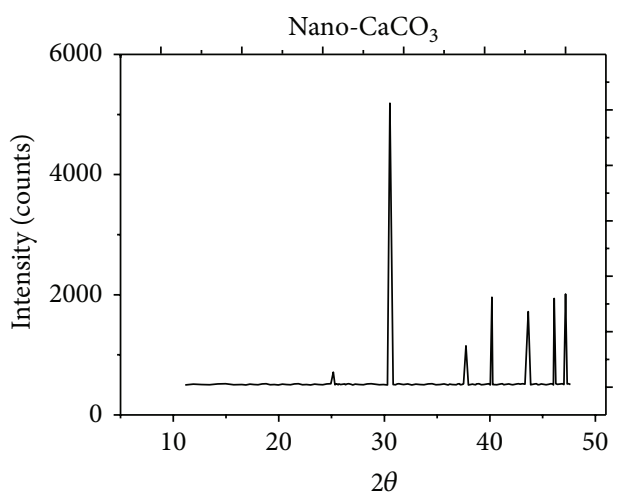

(g)

Figure 2: XRD curves of (a) pure CNT, (b) $\mathrm{NBCNT}_{1}$, (c) $\mathrm{NBCNT}_{2}$, (d) $\mathrm{NBCNT}_{3}$, (e) $\mathrm{NBCNT}_{4}$, (f) $\mathrm{NBCC}_{\text {, and }(\mathrm{g}) \text { nano-CaCO }}$. 


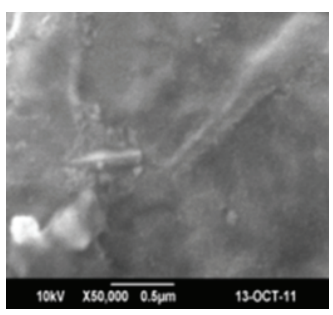

(a)

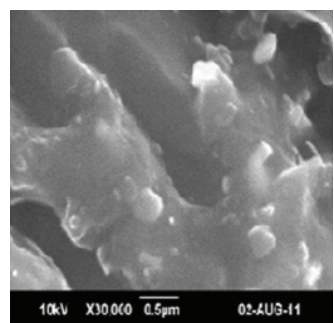

(e)

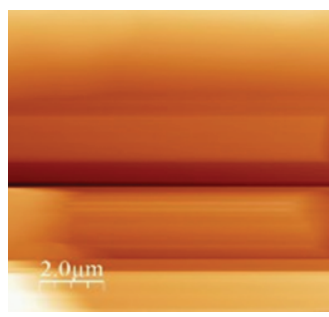

(i)

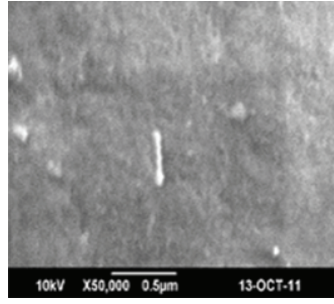

(b)

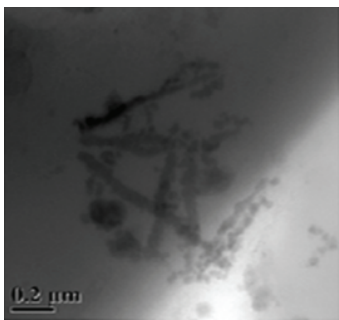

(f)

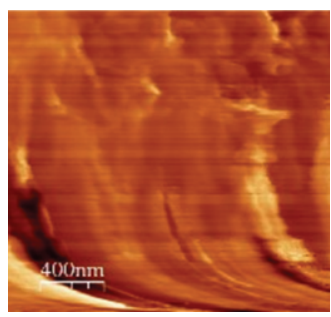

(j)

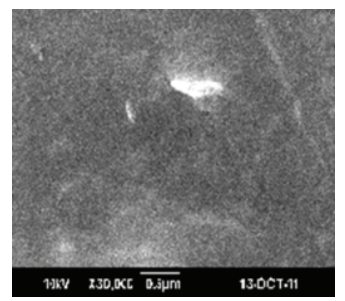

(c)

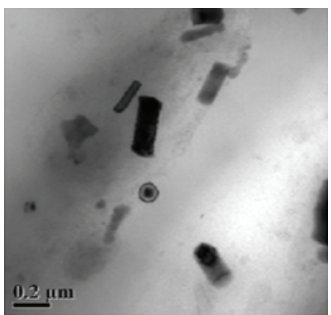

(g)

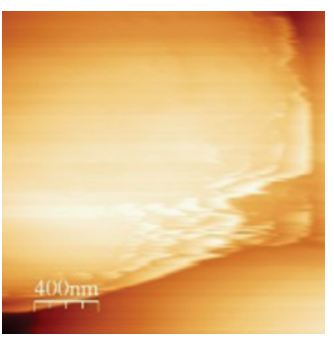

(k)

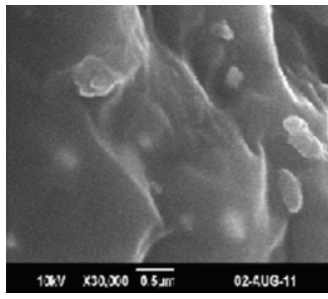

(d)

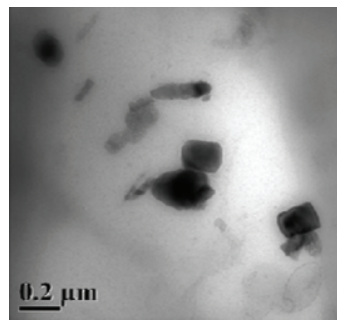

(h)

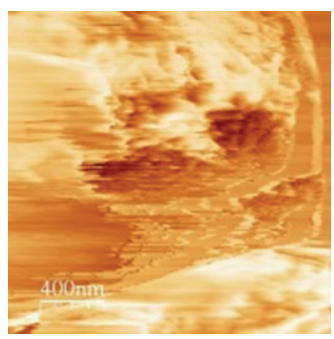

(1)

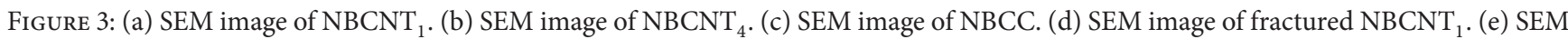
image of fractured $\mathrm{NBCNT}_{4}$. (f) TEM image of $\mathrm{NBCNT}_{1}$. (g) TEM image of $\mathrm{NBCNT}_{4}$. (h) TEM image of NBCC. (i) AFM height image of NBCC. (j) AFM phase image of NBCC. (k) AFM height image of $\mathrm{NBCNT}_{4}$. (l) AFM phase image of $\mathrm{NBCNT}_{4}$.

$7 \mathrm{phr}$ in $\mathrm{NBCNT}_{4}$, fracturing and agglomeration of CNTs occur as shown in the TEM image (Figure $3(\mathrm{~g})$ ). The TEM image of NBCC (Figure 3(h)) shows that the average length of the nano-SCC polygons is $113 \mathrm{~nm}$ and the breadth is $66 \mathrm{~nm}$. Agglomeration of the nanoparticles is also seen in the TEM image.

AFM images of the vulcanized rubber samples were taken on Multiview-1000 SPM (Nanonics Imaging, Ltd., Malcha, Jerusalem), in tapping mode. The AFM topographic (height) and phase images were taken in tapping mode. The height images barely show (Figures 3(i) and $3(\mathrm{k})$ ) the dark and bright regions corresponding to the valleys and hills in the surface [50-54]. But the phase images (Figure 3(j)) reveal the microstructure of the composites. The phase image of $\mathrm{NBCNT}_{4}$ (Figure 3(l)) shows more roughness than the phase image of NBCC (Figure 3(j)), indicating greater rubber-filler interaction in $\mathrm{NBCNT}_{4}$. The hills and valleys are due to the dispersion of filler particles.

3.1.4. Cure Properties. The curing behavior of rubber compound was measured using the automated Goettfert elastograph, model Vario 67.98 (German) at $150^{\circ} \mathrm{C}$. The cure properties of the NBR/NR nanocomposites containing different fillers are given in Table 2. Optimum cure time of the CNTfilled NBR/NR blend mixes decreased with the increase in the dosage of CNT from $1 \mathrm{phr}$ in $\mathrm{NBCNT}_{1}$ to $7 \mathrm{phr}$ in $\mathrm{NBCNT}_{4}$ as given in Table 2. The carboxyl groups on CNT could reduce the cure time compared with the SCC-filled mix NBCC. Like silica, PCS-filled mix (NBCS) showed a slight reduction in cure time, and the value was close to that of unfilled mix $\mathrm{NB}_{0}$. The scorch time slightly decreased with the increase in concentration of CNT as reported for NR [55]. The delta torque values of the mixes also exhibited an increase as the concentration of CNT was increased, indicating better cure state. Cure rate index values were in agreement with other results shown by the mixes.

Considering the various cure properties, it can be inferred that CNTs filled mixes are slightly superior to nano-SCC and nano-PCS-filled mixes. This can be due to more efficient dispersion of carboxyl-modified CNTs in the polymer matrix leading to intercalation when compared with SCC and PCS. The smaller particle size and larger surface area of CNTs could increase their dispersion in the polymer matrix. The polar groups on the CNT increased the interfacial interaction between polar NBR and nonpolar NR (Figure 4).

3.1.5. Tensile Properties. Studies on the effect of filler addition on tensile strength of natural and synthetic rubbers are available. Tensile strength provides information about strength and toughness of a material [56,57]. Tensile properties 
TABLE 2: Cure properties of NBR/NR blend mixes containing nano-SCC, -PCS, and CNT.

\begin{tabular}{lccccc}
\hline Mixes & Optimum cure time $t_{90}$ min. & Scorch time $\mathrm{ts}_{2}$ min. & Minimum torque $\mathrm{dNm}$ & Maximum torque dNm & Cure rate index $(\mathrm{CRI})$ \\
\hline $\mathrm{NBCNT}_{1}$ & 8.20 & 1.38 & 0.2 & 5.1 & 14.7 \\
$\mathrm{NBCNT}_{2}$ & 6.95 & 1.37 & 0.3 & 5.5 & 17.9 \\
$\mathrm{NBCNT}_{3}$ & 6.71 & 1.20 & 0.4 & 5.7 & 18.2 \\
$\mathrm{NBCNT}_{4}$ & 5.74 & 1.11 & 0.8 & 5.2 & 21.6 \\
$\mathrm{NBCC}$ & 8.14 & 1.28 & 0.5 & 5.2 & 14.6 \\
$\mathrm{NBCS}$ & 5.81 & 1.48 & 0.3 & 5.2 & 23.1 \\
$\mathrm{NB}_{0}$ & 5.9 & 1.21 & 0.5 & 5.4 & 21.3 \\
\hline
\end{tabular}

TABLE 3: Technological properties of NBR/NR blend mixes containing nano-SCC, -PCS, and CNT.

\begin{tabular}{lccccccccc}
\hline Mixes & $\begin{array}{c}\text { TS } \\
\text { MPa }\end{array}$ & $\begin{array}{c}300 \% \mathrm{M} \\
\mathrm{MPa}\end{array}$ & $\begin{array}{c}\mathrm{EB} \\
\%\end{array}$ & $\begin{array}{c}\mathrm{TR} \\
\mathrm{N} / \mathrm{mm}\end{array}$ & $\begin{array}{c}\text { Hardness } \\
\text { Shore A }\end{array}$ & $\begin{array}{c}\mathrm{AL} \\
\mathrm{mm}^{3}\end{array}$ & $\begin{array}{c}\mathrm{CS} \\
\%\end{array}$ & $\begin{array}{c}\Delta \mathrm{G} \\
\mathrm{J} / \mathrm{mol}\end{array}$ & $\begin{array}{c}\Delta \mathrm{S} \\
\mathrm{J} / \mathrm{mol} / \mathrm{K}\end{array}$ \\
\hline $\mathrm{NBCNT}_{1}$ & 4.36 & 2.54 & 463 & 21.52 & 37 & 161.13 & 3.85 & -27.08 & 0.0902 \\
$\mathrm{NBCNT}_{2}$ & 6.64 & 3.33 & 490 & 28.5 & 41 & 139.76 & 3.91 & -27.96 & 0.0932 \\
$\mathrm{NBCNT}_{3}$ & 7.83 & 4.12 & 519 & 36.49 & 43 & 137.12 & 4.08 & -30.0 & 0.100 \\
$\mathrm{NBCNT}_{4}$ & 8.45 & 4.76 & 542 & 37.21 & 48 & 135.32 & 4.14 & -31.01 & 0.1034 \\
$\mathrm{NBCC}^{2}$ & 3.86 & 2.21 & 445 & 20.71 & 40 & 175.26 & 3.32 & -26.12 & 0.0871 \\
$\mathrm{NBCS}$ & 5.81 & 2.60 & 429 & 18.11 & 37 & 179.19 & 3.46 & -26.08 & 0.0869 \\
$\mathrm{NB}_{0}$ & 3.79 & 2.11 & 379 & 14.97 & 34 & 191.09 & 3.95 & -26.54 & 0.0885 \\
\hline
\end{tabular}

TS: tensile strength, M: modulus, EB: elongation at break, TR: tear resistance, CS: compression set, AL: abrasion loss, and SV: swelling value.

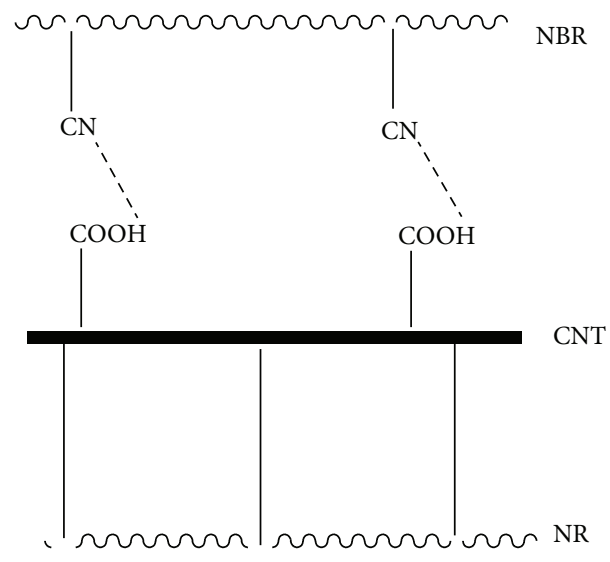

FIGURE 4: NR/NBR compatibilization by carboxylated CNT.

of the vulcanizates were measured on a Universal Testing Machine, Instron Corporation, series IX model 1034, using a crosshead speed of $500 \mathrm{~mm} / \mathrm{min}$ as ASTM procedure D412-87 and using dumbbell specimen. Five samples of each vulcanized sheet were used for the measurement. The values were directly obtained from the instrument. Tensile strength and modulus were reported in MPa and elongation at break in percentage. Table 3 shows that tensile strength is higher for vulcanizates containing modified CNT compared with those containing silicate-coated calcium carbonate and PEO-coated calcium silicate indicating that polymer-filler interaction is more for the mixes containing CNT, as evident from the bound rubber content (Figure 5). Compatibilization and miscibility between NR and NBR is also more for CNT mixes, as clear from the SEM and TEM images (Figure 3);

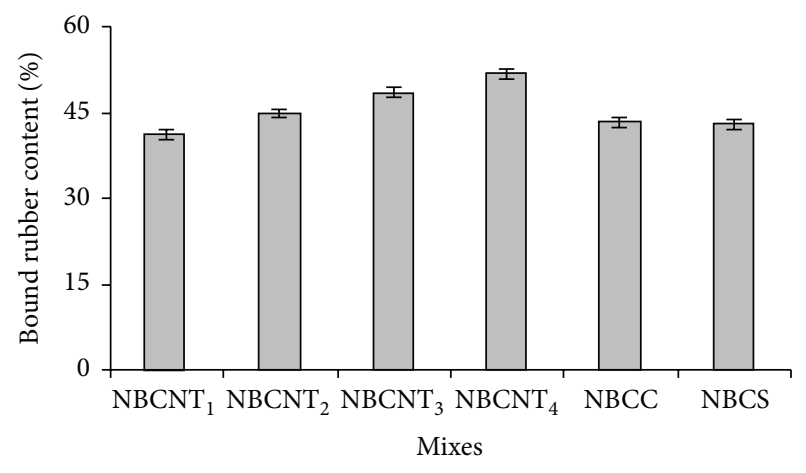

FIGURE 5: Variation of bound rubber content with filler.

that is, foldings are minimum in the images. As the dosage of the modified CNT having much higher aspect ratio increases, surface area available to the polymer will increase, resulting in high polymer-filler interaction and intercalation of polymer into the CNTs. The spherical shape and lower aspect ratio of SCC and PCS caused lower polymer-filler interaction in NBCC and NBCS, as evident from the microscopic images (Figure 3).

Table 3 shows that the elongation at break (EB) percent was higher for CNT-filled mixes compared with those containing SCC and PCS due to superior polymer-filler interaction possible in CNT mixes. As the dosage of CNT increased from 1 phr in $\mathrm{NBCNT}_{1}$ to $7 \mathrm{phr}$ in $\mathrm{NBCNT}_{4}, \mathrm{~EB}$ percent also increased unlike in conventional composites probably due to the plasticizing or sliding effect [58], as clear from the SEM images (Figures 3(d) and 3(e)). Also, miscibility of NR in NBR was increased due to the binding 
action of CNT containing polar groups. The nonpolar part of CNT interacts with the nonpolar NR, and the polar groups on CNT interact with polar end of NBR, causing an improvement in miscibility of the two rubbers.

Modulus of the CNT-filled mixes was also higher compared with SCC- and PCS-filled mixes. Also, an increase in modulus was observed (Table 3 ) when the dosage of CNT was increased from $1 \mathrm{phr}$ in $\mathrm{NBCNT}_{1}$ to $7 \mathrm{phr}$ in $\mathrm{NBCNT}_{4}$. This can be attributed to the high polymer-filler interaction in these vulcanizates as described above.

3.1.6. Other Mechanical Properties. Tear resistance values of the NBR/NR nanocomposites are given in Table 3. The test samples were cut from the vulcanized sheets parallel to the grain direction. The test pieces were mounted on a Universal Testing Machine, Instron Corporation, series IX, model 1034, using a crosshead speed of $500 \mathrm{~mm} / \mathrm{min}$ as per ASTM method D624-98. Five samples of each vulcanized sheet were used for the measurement. Tear resistance was directly obtained in $\mathrm{N} / \mathrm{mm}$. All of the CNT-filled vulcanizates exhibited superior tear resistance compared with SCC- and PCS-filled vulcanizates. Also, as the dosage of CNT was increased from $1 \mathrm{phr}$ in $\mathrm{NBCNT}_{1}$ to $7 \mathrm{phr}$ in $\mathrm{NBCNT}_{4}$, there was a $73 \%$ increase in tear resistance. This is because of the better dispersion of CNTs in the polymer matrix and the higher filler-polymer interaction, as evident from the bound rubber content (Figure 5) and microscopic images (Figure 3). The CNTs have suitable shape and geometry to prevent crack propagation more effectively than NBCC and NBCS [59].

Hardness values (Shore A) of the vulcanizates are also given in Table 3. The CNT-filled mixes exhibited more hardness than the SCC- and PCS-filled mixes, particularly at 5 and $7 \mathrm{phr}$ of CNTs. This is due to the extra strength of CNT and also due to the superior polymer-filler interaction possible for CNT-NBR/NR systems. The high bound rubber content of CNT-filled mixes (Figure 5) is an indication of high polymerfiller interaction.

Compression set was determined as per ASTM D39589 (method B) using the apparatus manufactured by Prolific Engineers India, Ltd. The moulded samples $(1.25 \mathrm{~cm}$ thick and $2.8 \mathrm{~cm}$ in diameter) compressed to constant deflection (25\%) were kept for $22 \mathrm{hrs}$ at $27^{\circ} \mathrm{C}$. The samples were taken out, and after keeping for $30 \mathrm{~min}$, the final thickness was measured. Three samples of each mix were used for compression set determination. The CNT-filled vulcanizates showed high compression set values as given in Table 3, compared with the NBCC and NBCS. This can be attributed to the reduction in the elasticity of the composites with an increase in MWNT dosage [60].

Abrasion loss was measured using DIN abrader (DIN 53516). A moulded sample having a diameter of $6 \pm 0.2 \mathrm{~mm}$ and a thickness of $6 \mathrm{~mm}$ was inserted into the sample holder so that $2 \mathrm{~mm}$ of the sample remained exposed and was allowed to move across the surface of an abrasive sheet mounted on a rotating drum. Weight of the test specimen was noted before and after the test. The difference in weight was converted into volume loss by dividing the weight loss with the density of the specimen. Three moulded samples

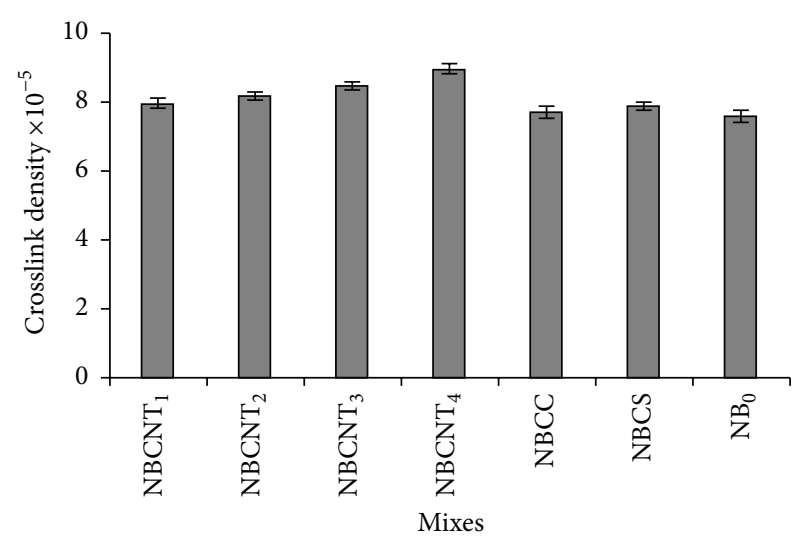

FIGURE 6: Variation of crosslink density with filler dosage.

of each mix were used for the determination of abrasion loss, and the final result was expressed as the average of these results. Abrasion resistance of CNT-filled vulcanizates was superior to that of the SCC- and PCS-filled vulcanizates (Table 3). As the dosage of CNT was increased, abrasion loss decreased (abrasion resistance increased). The reinforcing action of CNT has improved the abrasion resistance of CNTfilled mixes.

3.2. Extent of Reinforcement: Thermodynamic Parameter Analysis. Cross-link density (CD) values of the vulcanizates estimated using toluene are represented in Figure 6. Circular samples of approximately $1 \mathrm{~cm}$ diameter and $0.2 \mathrm{~cm}$ thickness were punched out from the central portions of the vulcanizate and weighed. These samples were allowed to swell in toluene at room temperature to allow the swelling to reach equilibrium. The CNT-filled nanocomposites possessed higher CD than the gum and those filled with SCC and PCS. As the dosage of CNT was increased from $1 \mathrm{phr}$ in $\mathrm{NBCNT}_{1}$ to $7 \mathrm{phr}$ in $\mathrm{NBCNT}_{4}$, crosslink density also increased. The higher cross-link density of the CNT-filled mixes shows the reinforcing action of CNT in the NBR/NR blend. The blend became more cross-linked in presence of the modified CNT due to the intercalation of polymer chain segments into the tube space of CNT. The increased crosslink density puts restraint on the network which could result in enhanced tensile properties. The lower aspect ratio and less appropriate geometry of SCC and PCS (as evident from the TEM images) compared with CNT resulted in comparatively poor polymerfiller interaction in NBCC and NBCS and hence lower CD and tensile strength.

Thermodynamic parameters like the free energy change $(\Delta G)$ and the entropy change $(\Delta S)$ were estimated for the nanocomposites using (1) and (2), respectively [61], and the values are given in Table 3. Consider the following:

$$
\begin{gathered}
\Delta G=R T\left[\ln \left(1-V_{r}\right)+V_{r}+\chi V_{r}^{2}\right], \\
\Delta S=\frac{\Delta G}{T},
\end{gathered}
$$


where $\chi$ is the interaction parameter, $V_{r}$ is the volume fraction of rubber, and $T$ is temperature in Kelvin.

The CNT-filled vulcanizates showed larger negative values of free energy change (Table 3) compared with SCC- and PCS-filled vulcanizates, which indicates better compatibility between the filler and polymer matrix in CNT-filled mixes. The negative value of change in free energy increased with the dosage of CNT indicating increased filler-polymer interaction and increased NBR/NR miscibility. Similarly, the CNTfilled mixes possessed more entropy change (Table 3). Also, the change in entropy increased with the increase in dosage of CNT. These results also support the increased compatibility between the filler and the polymer. This is a further proof of the intercalation of the polymer into the tube space of CNTs.

3.3. Oil Resistance. The effect of addition of fillers on the oil resistance of the vulcanizates was analyzed using oil swelling coefficients $(\sigma)$ of circular samples $(2 \mathrm{~cm}$ in diameter) immersed in $2 \mathrm{~T}$ oil for 5 days. The swelling coefficients were calculated using the following [34]:

$$
\sigma=\frac{\left(W_{s}-W_{i}\right)}{W_{i} \times \rho},
$$

where $W_{s}$ is the weight of swollen sample, $W_{i}$ is the initial weight of the sample, and $\rho$ is the density of rubber. Swelling coefficients decreased with increase in dosage of CNT as shown in Figure 7, due to the improved barrier property of the nanocomposites containing higher dosage of the nanofiller.

\section{Summary and Conclusions}

The carboxylated CNT-filled NBR/NR blend mixes showed better cure properties when cured with nanomodified BIAT and micro-CBS binary system. Cure time decreased with the increase in concentration of CNT. The delta torque values of the CNT-filled mixes increased with the increase in concentration of CNT. These improved cure properties were due to the better dispersion of CNT by increasing the filler-polymer interaction leading to intercalation of polymer matrix, as compared with silicate-coated calcium carbonate and PEO-coated calcium silicate. The polar groups on CNT could increase the NBR/NR compatibilization. The XRD curves and microscopic images provide support for the better mixing of CNT compared with silicate-coated calcium carbonate and PEO-coated calcium silicate. The improved mixing has led to the enhancement of the technological properties like tensile strength, modulus, elongation at break $\%$ values, tear strength, abrasion resistance, bound rubber content, and hardness. The enhanced crosslink density values are in agreement with other technological properties. The elongation at break \% values increased with the increase in the dosage of CNT because of the sliding effect. The CNT-filled vulcanizates exhibited improved oil resistance, compared with the vulcanizates containing inorganic fillers. This is due to the improved barrier property imparted by the better dispersed CNT. Tortuous paths were created in presence of CNTs.

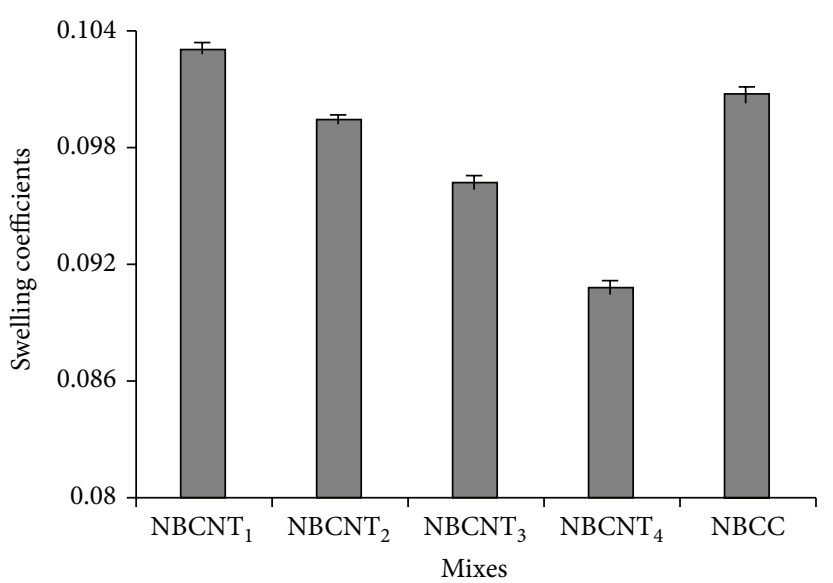

FIGURE 7: Oil swelling coefficients of NBR/NR nanocomposites.

\section{Acknowledgment}

University Grants Commission of India is greatly acknowledged for providing financial assistance to carry out this work.

\section{References}

[1] S. Datta and D. Lohse, Polymeric Compatibilizers, Hanser, New York, NY, USA, 1996.

[2] G. O. Shonaike and G. P. Simon, Eds., Polymer Blends and Alloys, Marcel Dekker, New York, NY, USA, 1999.

[3] I. S. Miles and S. Rostami, Eds., Multi Component Polymer Systems, Longman Scientific and Technical, London, UK, 1992.

[4] L. A. Utracki, Ed., Polymer Blends Handbook, vol. 1-2, Kluwer Academic, Dordrecht, The Netherlands, 2002.

[5] A. J. Tinker, "Crosslink distribution and interfacial adhesion in vulcanized blends of NR and NBR," Rubber Chemistry and Technology, vol. 63, no. 4, pp. 503-515, 1990.

[6] P. Arjunan, US Patent 5352739, 1994.

[7] M. N. Ismail, S. H. El-Sabbagh, and A. A. Yehia, "Fatigue and mechanical properties of NR/SBR and NR/NBR blend vulcanizates," Journal of Elastomers and Plastics, vol. 31, no. 3, pp. 255-270, 1999.

[8] A. Abdellah and L. A. Utracki, "Interphase and compatibilization of polymer blends," Polymer Engineering and Science, vol. 36, no. 12, pp. 1574-1585, 1996.

[9] A. J. Tinker, Blends of Natural Rubber with Speciality Synthetic Rubbers in Industrial Composites Based on Natural Rubber, Malaysian Rubber Research and Development Board, Kualampur, Malaysia, 1998.

[10] M. A. Kader, W. D. Kim, S. Kaang, and C. Nah, "Morphology and dynamic mechanical properties of natural rubber/nitrile rubber blends containing trans-polyoctylene rubber as a compatibilizer," Polymer International, vol. 54, no. 1, pp. 120-129, 2005.

[11] C. Sirisinha, S. Limcharoen, and J. Thunyarittikom, "Oil resistance controlled by phase morphology in natural rubber/nitrile rubber blends," Journal of Applied Polymer Science, vol. 87, no. 1, pp. 83-89, 2003.

[12] A. E. Mathai, R. P. Singh, and S. Thomas, "Transport of substituted benzenes through nitrile rubber/natural rubber 
blend membranes," Journal of Membrane Science, vol. 202, no. 1-2, pp. 35-54, 2002.

[13] M. Li, Y. Li, J. Zhang, and S. Feng, "Effect of compatibilizers on the miscibility of natural rubber/silicone rubber blends," Polymer Engineering \& Science, 2013.

[14] S. Angnanon, P. Prasassarakich, and N. Hinchiranan, "Styrene/acrylonitrile graft natural rubber as compatibilizer in rubber blends," Polymer, vol. 50, no. 11, pp. 1170-1178, 2011.

[15] W. G. Hwang, K. H. Wei, and C. M. Wu, "Mechanical, thermal, and barrier properties of NBR/organosilicate nanocomposites," Polymer Engineering \& Science, vol. 44, no. 11, pp. 2117-2124, 2004.

[16] H. H. Le, S. Ilisch, and H.-J. Radusch, "Characterization of the effect of the filler dispersion on the stress relaxation behavior of carbon black filled rubber composites," Polymer, vol. 50, no. 10, pp. 2294-2303, 2009.

[17] A. Mostafa, A. Abouel-Kasem, M. R. Bayoumi, and M. G. ElSebaie, "Effect of carbon black loading on the swelling and compression set behavior of SBR and NBR rubber compounds," Materials and Design, vol. 30, no. 5, pp. 1561-1568, 2009.

[18] C. Kantala, E. Wimolmala, C. Sirisinha, and N. Sombatsompop, "Reinforcement of compatibilized NR/NBR blends by fly ash particles and precipitated silica," Polymers for Advanced Technologies, vol. 20, no. 5, pp. 448-458, 2009.

[19] W. E. Gacitua, A. A. Ballerini, and J. Zhang, "Polymer nanocomposites: synthesis and natural fillers a review," Maderas. Ciencia y Tecnología, vol. 7, pp. 159-178, 2005.

[20] M. Alexandre and P. Dubois, "Polymer-layered silicate nanocomposites: preparation, properties and uses of a new class of materials," Materials Science and Engineering R, vol. 28, no. 1-2, pp. 1-63, 2000.

[21] K. Yoshikai, T. Oshaki, and M. Furukava, "Silica reinforcement of synthetic diene rubbers by sol-gel process in the latex," Journal of Applied Polymer Science, vol. 85, pp. 2053-2063, 2002.

[22] M. Nasir, B. T. Poh, and P. S. Ng, "Effect of $\gamma$-mercaptopropyltrimethoxysilane coupling agent on $t 90$, tensile strength and tear strength of silica-filled NR, NBR and SBR vulcanizates," European Polymer Journal, vol. 24, no. 10, pp. 961-965, 1988.

[23] S. N. Chakravarty and A. Chakravarty, "Reinforcement of rubber compounds with nano-filler," KGK Kautschuk Gummi Kunststoffe, vol. 60, no. 11, pp. 619-622, 2007.

[24] A. Choudhury, A. K. Bhowmick, and C. Ong, "Effect of different nanoparticles on thermal, mechanical and dynamic mechanical properties of hydrogenated nitrile butadiene rubber nanocomposites," Journal of Applied Polymer Science, vol. 116, no. 3, pp. 1428-1441, 2010.

[25] P. C. Thomas, E. T. Jose, P. S. Thomas, S. Thomas, and K. Joseph, "High-performance nanocomposites based on arcylonitrilebutadiene rubber with fillers of different particle size: mechanical and morphological studies," Polymer Composites, vol. 31, no. 9, pp. 1515-1524, 2010.

[26] M. Moniruzzaman and K. I. Winey, "Polymer nanocomposites containing carbon nanotubes," Macromolecules, vol. 39, no. 16, pp. 5194-5205, 2006.

[27] A. Fakhru'l-Razi, A. A. Muataz, G. Nazlia et al., "Effect of multiwall carbon nanotubes on the mechanical properties of natural rubber," Composite Structures, vol. 75, no. 1-4, pp. 496-500, 2006.

[28] G. Sui, W. H. Zhong, X. P. Yang, Y. H. Yu, and S. H. Zhao, "Preparation and properties of natural rubber composites reinforced with pretreated carbon nanotubes," Polymers for Advanced Technologies, vol. 19, no. 11, pp. 1543-1549, 2008.
[29] N. Girun, F.-R. Ahmadun, S. A. Rashid, and M. A. Atieh, "Multi-wall carbon nanotubes/Styrene Butadiene Rubber (SBR) nanocomposite," Fullerenes Nanotubes and Carbon Nanostructures, vol. 15, no. 3, pp. 207-214, 2007.

[30] H. Zhao, S. Qi, W. Zhou, and N. Liu, "Progress in carbon nanotube/rubber composites," Hecheng Xiangjiao Gongye, vol. 31, no. 4, pp. 315-318, 2008.

[31] G. Sui, W. H. Zhong, X. P. Yang, and Y. H. Yu, "Curing kinetics and mechanical behavior of natural rubber reinforced with pretreated carbon nanotubes," Materials Science and Engineering A, vol. 485, no. 1-2, pp. 524-531, 2008.

[32] H. Lorenz, J. Fritzsche, A. Das et al., "Advanced elastomer nanocomposites based on CNT-hybrid filler systems," Composites Science and Technology, vol. 69, no. 13, pp. 2135-2143, 2009.

[33] L. Lu, Y. Zhai, Y. Zhang, C. Ong, and S. Guo, "Reinforcement of hydrogenated carboxylated nitrile-butadiene rubber by multiwalled carbon nanotubes," Applied Surface Science, vol. 255, no. 5, pp. 2162-2166, 2008.

[34] A. M. Omran, A. M. Youssef, M. M. Ahmed, E. M. AbdelBary, and R. T. L. Hellipolis, "Mechanical and oil resistance characteristics of rubber blends based on nitrile butadiene rubber," KGK Kautschuk Gummi Kunststoffe, vol. 63, no. 5, pp. 197-202, 2010.

[35] P. Kueseng, P. Sae-oui, and N. Rattanasom, "Mechanical and electrical properties of natural rubber and nitrile rubber blends filled with multi-wall carbon nanotube," Polymer Testing, vol. 32, pp. 731-738, 2013.

[36] F. H. Gojny, M. H. G. Wichmann, B. Fiedler et al., "Evaluation and identification of electrical and thermal conduction mechanisms in carbon nanotube/epoxy composites," Polymer, vol. 47, no. 6, pp. 2036-2045, 2006.

[37] Y. J. Kim, T. S. Shin, H. D. Choi, J. H. Kwon, Y.-C. Chung, and H. G. Yoon, "Electrical conductivity of chemically modified multiwalled carbon nanotube/epoxy composites," Carbon, vol. 43, no. 1, pp. 23-30, 2005.

[38] Y. S. Song and J. R. Youn, "Influence of dispersion states of carbon nanotubes on physical properties of epoxy nanocomposites," Carbon, vol. 43, no. 7, pp. 1378-1385, 2005.

[39] P. M. Ajayan, L. S. Schadler, C. Giannaris, and A. Rubio, "Single-walled carbon nanotube-polymer composites: strength and weakness," Advanced Materials, vol. 12, no. 10, pp. 750-753, 2000.

[40] Li. Xu, S. Y. Wong, W. C. Tjiu, B. P. Lyons, S. A. Oh, and C. B. $\mathrm{He}$, "Quantitative inhibiting effect of Group I-III cations on the growth of carbon nanotubes," Carbon, vol. 46, no. 5, pp. 818-821, 2008.

[41] Z. Ali, H. H. Le, S. Ilisch, T. Thurn-Albrecht, and H.-J. Radusch, "Morphology development and compatibilization effect in nanoclay filled rubber blends," Polymer, vol. 51, no. 20, pp. 45804588, 2010.

[42] A. Das, K. W. Stöckelhuber, R. Jurk et al., "Modified and unmodified multiwalled carbon nanotubes in high performance solution-styrene-butadiene and butadiene rubber blends," Polymer, vol. 49, no. 24, pp. 5276-5283, 2008.

[43] D. Yue, Y. Liu, Z. Shen, and L. Zhang, "Study on preparation and properties of carbon nanotubes/rubber composites," Journal of Materials Science, vol. 41, no. 8, pp. 2541-2544, 2006.

[44] H. Tahermansouri, D. Chobfrosh, and M. Meskinfam, "Functionalization of Carboxylated Multi-wall Nanotubes with 1,2phenylenediamine," International Journal of Nano Dimension, vol. 1, pp. 153-158, 2010. 
[45] A. Tavangar, B. Tan, and K. Venkatakrishnan, "Synthesis of three-dimensional calcium carbonate nanofibrous structure from eggshell using femtosecond laser ablation," Journal of Nanobiotechnology, vol. 9, article 1, 2011.

[46] S. Mishra and N. G. Shimpi, "Comparison of nano $\mathrm{CaCO}_{3}$ and flyash filled with styrene butadiene rubber on mechanical and thermal properties," Journal of Scientific \& Industrial Research, vol. 64, pp. 744-751, 2005.

[47] A. Gupta, H. S. Bhatti, D. Kumar, N. K. Verma, and R. P. Tandon, "Nano and bulk crystals of $\mathrm{ZnO}$ : synthesis and characterization," Digest Journal of Nanomaterials and Biostructures, vol. 1, no. 1, pp. 1-9, 2006.

[48] K. Khairurrijal, M. Abdullah, M. Rosi, and F. A. Noor, "Structural characteristics of carbon nanotubes fabricated using simple spray pyrolysis method," Indonesian Journal of Physics, vol. 19, no. 3, pp. 91-95, 2008.

[49] H. Li, C. Liu, and S. Fan, "Homogeneous carbon nanotube/carbon composites prepared by catalyzed carbonization approach at low temperature," Journal of Nanomaterials, vol. 2011, Article ID 281490, 5 pages, 2011.

[50] P. Zhang, X. Shi, G. Yu, and S. Zhao, "The structure change of dynamically fatigued unfilled natural rubber vulcanizates," Journal of Applied Polymer Science, vol. 115, no. 6, pp. 3535-3541, 2010.

[51] J. Oderkerk, G. De Schaetzen, B. Goderis, L. Hellemans, and G. Groeninckx, "Micromechanical deformation and recovery processes of nylon-6/ rubber thermoplastic vulcanizates as studied by atomic force microscopy and transmission electron microscopy," Macromolecules, vol. 35, no. 17, pp. 6623-6629, 2002.

[52] A. Ghosh, R. S. Rajeev, S. K. De, W. Sharp, and S. Bandyopadhyaya, "Atomic force microscopic studies on the silicone rubberfluororubber blend containing ground rubber vulcanizate powder," Journal of Elastomers and Plastics, vol. 38, no. 2, pp. 119-132, 2006.

[53] A. Ghosh, R. S. Rajeev, S. K. De, W. Sharp, and S. Bandyopadhyaya, "Atomic force microscopic studies on the silicone rubberfluororubber blend containing ground rubber vulcanizate powder," Journal of Elastomers and Plastics, vol. 38, no. 2, pp. 119-132, 2006.

[54] H. H. Le, Q. Zia, S. Ilisch, and H.-J. Radusch, "Effect of extender oils on the stress relaxation behavior of thermoplastic vulcanizates," Express Polymer Letters, vol. 2, no. 11, pp. 791-799, 2008.

[55] H. Ismail, F. Ramly, and N. Othman, "Multiwall carbon nanotube-filled natural rubber: the effects of filler loading and mixing method," Polymer, vol. 49, no. 3, pp. 260-266, 2010.

[56] A. Usuki, Y. Kojima, M. Kawasumi et al., "Synthesis of nylon 6-clay hybrid," Journal of Materials Research, vol. 8, no. 5, pp. 1179-1184, 1993.

[57] J. H. Shim, E. S. Kim, J. H. Joo, and J. S. Yoon, "Properties and morphology of poly(L-lactide)/clay composites according to the clay modification," Journal of Applied Polymer Science, vol. 102, no. 5, pp. 4983-4988, 2006.

[58] H. Essawy and D. El-Nashar, "The use of montmorillonite as a reinforcing and compatibilizing filler for NBR/SBR rubber blend," Polymer Testing, vol. 23, no. 7, pp. 803-807, 2004.

[59] M. S. Kim, G. H. Kim, and S. R. Chowdhury, "Polybutadiene rubber/organoclay nanocomposites: effect of organoclay with various modifier concentrations on the vulcanization behavior and mechanical properties," Polymer Engineering \& Science, vol. 47, no. 3, pp. 308-313, 2007.
[60] M. A. Atieh, "Effect of functionalize carbon nanotubes with amine functional group on the mechanical and thermal properties of styrene butadiene rubber," Journal of Thermoplastic Composite Materials, vol. 24, no. 5, pp. 613-624, 2011.

[61] D. S. Camphell, "Structural characterization of vulcanizates part $\mathrm{X}$. Thiol-disulfide interchange for cleaving disulfide crosslinks in natural rubber vulcanizates," Journal of Applied Polymer Science, vol. 13, pp. 1201-1214, 1969. 

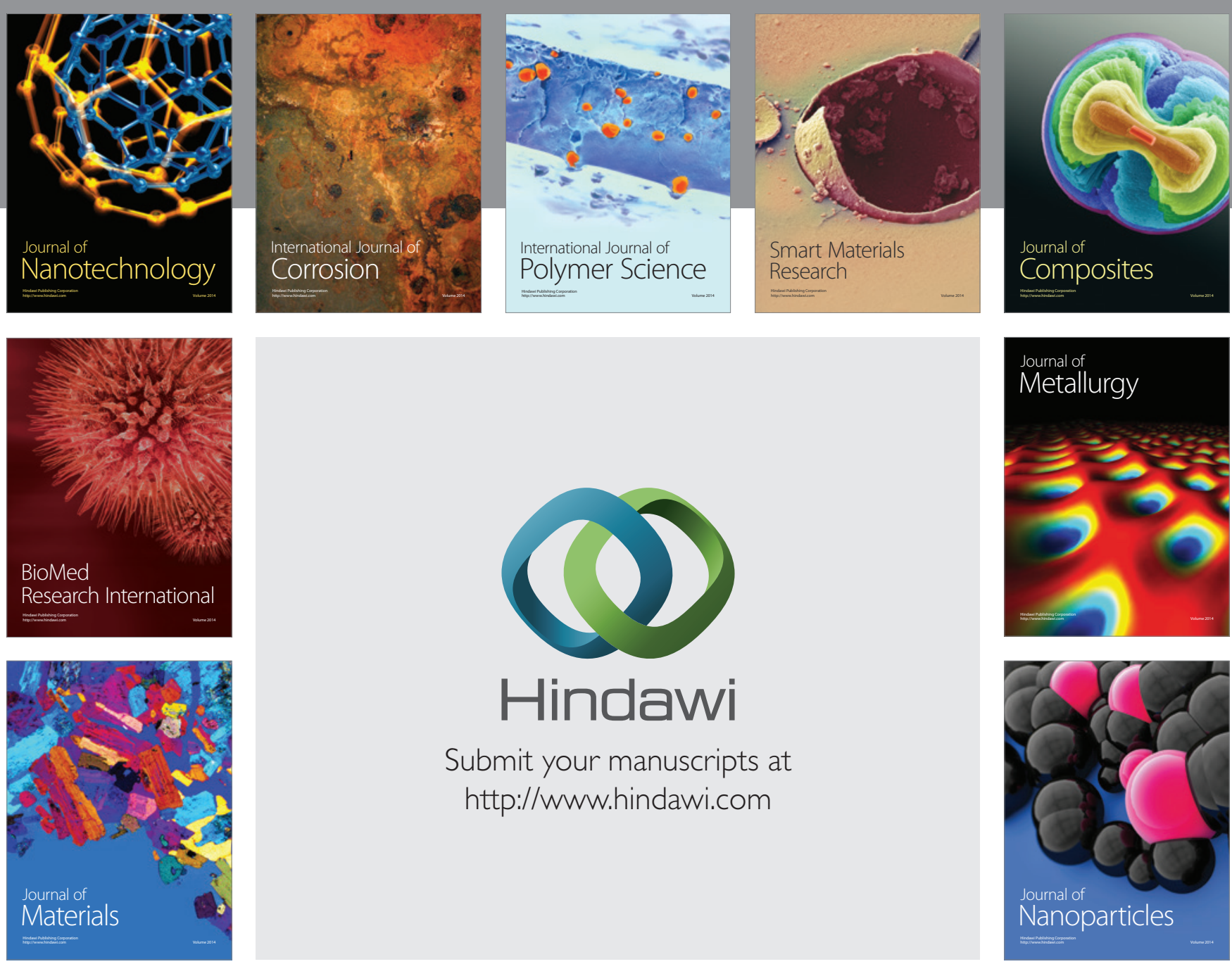

Submit your manuscripts at http://www.hindawi.com
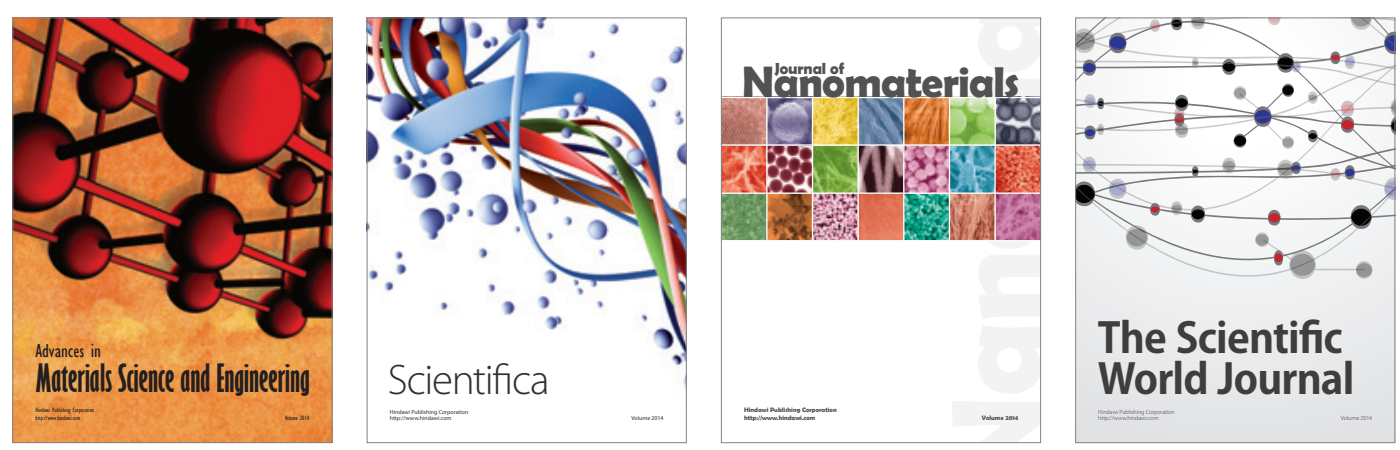

\section{The Scientific World Journal}
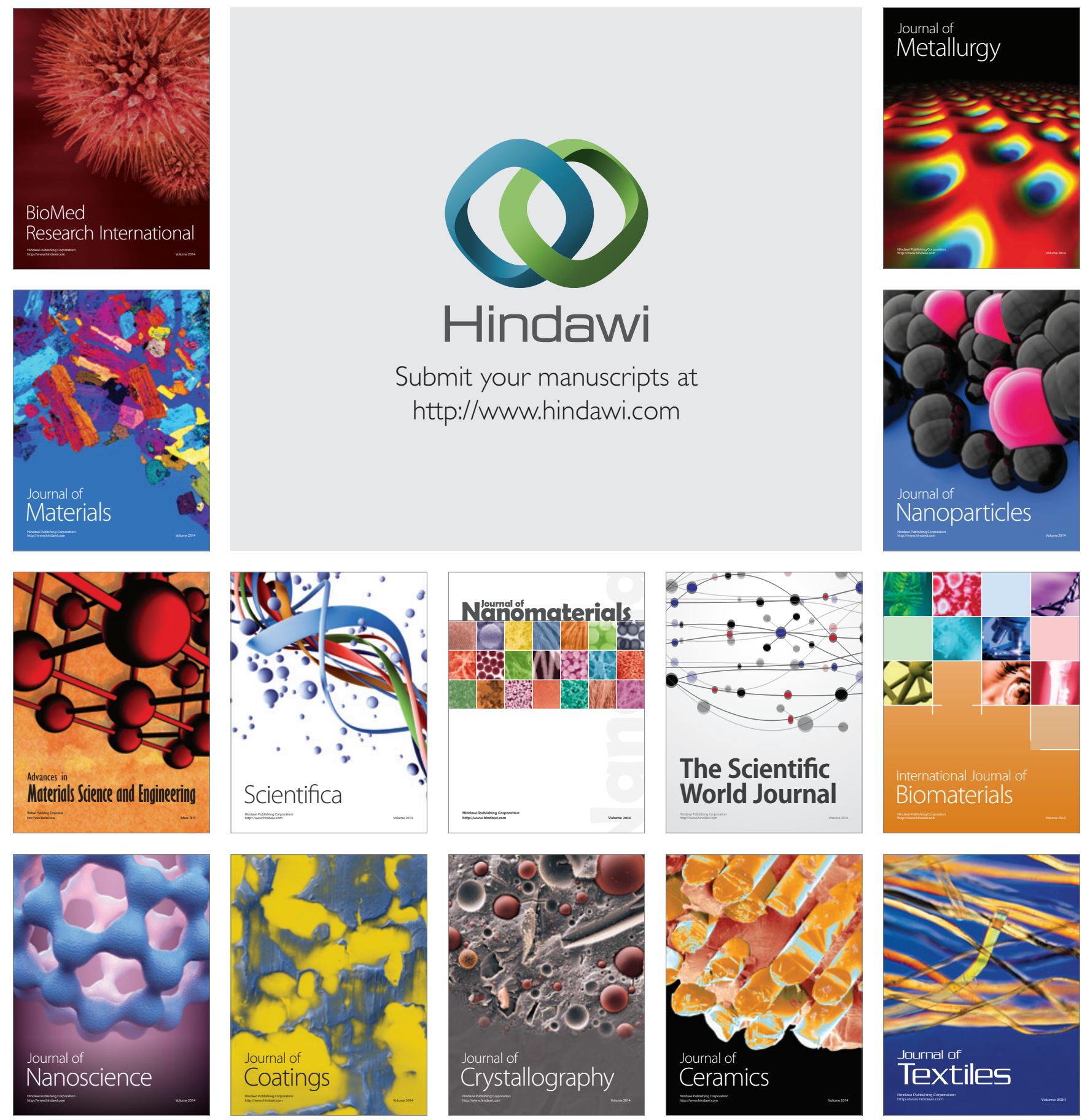